\title{
LXXXI. On the principal series in the spectra of the alkali metals
}

\section{W. Marshall Watts D.Sc.}

To cite this article: W. Marshall Watts D.Sc. (1915) LXXXI. On the principal series in the spectra of the alkali metals, Philosophical Magazine Series 6, 29:174, 775-783, DOI: 10.1080/14786440608635360

To link to this article: http://dx.doi.org/10.1080/14786440608635360

曲 Published online: 08 Apr 2009.

Submit your article to this journal $\sqsubset \pi$

Џ Article views: 3

Q View related articles $\square$

Citing articles: 1 View citing articles 5 
inversely as the fourth power of the distance, seems to show that the atom of iron must come under one of the special cases above mentioned, having a centre ring with only one or two electrons. The force in this case may be inversely as the square of the distance. This is shown by the equations for the hydrogen atom, (48) and (49) above, where the first term due to the magnetic force contains the inverse second power of the distance, showing that for hydrogen atoms at a great distance, having parallel axes, the attraction is inversely as the square of the distance. This suggests that possibly the rings of electrons in fig. $3^{*}$ of the former paper are correct, for there iron and cobalt have a single central electron, and nickel two central electrons, which will give rise to the same law of variation of the force with the distance as that in hydrogen.

In this paper the positive charge in each atom is supposed to be at rest free from vibration of its whole mass, and long waves of radiant heat are attributed to the vibration of this mass. The period of this vibration in the hydrogen molecule was given in the former paper. It should be considered, therefore, that the work in this paper applies to the state of matter at the absolute zero of temperature.

LXXXI. On the Principal Series in the Spectra of the Alkali Metals. By W. Marshald Wat'Ts, D.Sc. $†$

TN the Philosophical Magazine for 1908 (xvi. p. 945) 1 Wood describes the absorption spectrum of sodium vapour in which he measured 48 lines of the principal series forming the most extended "Balmer series" hitherto observed.

Bevan $\ddagger$ applied Wood's method to the other alkali metals, and observed extended series in lithium, potassium, rubidium, and cæsium. He also discusses the representation of these long series by formulæ, obtaining very close results by the use of the formula employed by Mogendorff in 1906 and by Hicks in 1910, viz.,

$$
\mathrm{O} . \mathrm{F} .=\mathrm{C} . \mathrm{F} .-\frac{109675}{\left(m+\mu+\frac{c}{m}\right)^{2}}
$$

* Loc. cit.

+ Communicated by the Author.

$\ddagger$ Proc. Roy. Soc. Ixxxiii. p. 423 (1910), Ixxxiv. p. 2C9, Ixxxv. pp. 54, 55, lxxxvi. p. 300 (1911). 


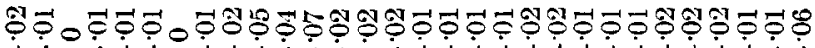

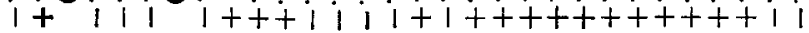

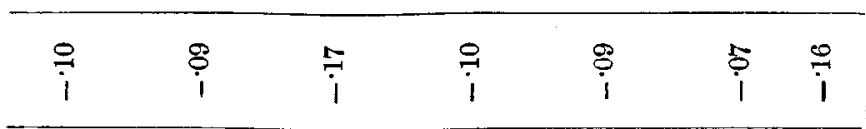

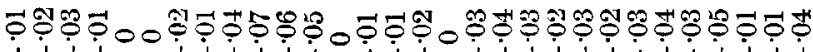

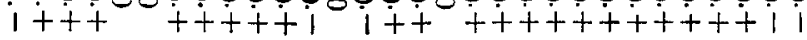

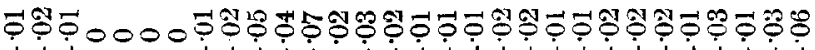
$1+\dot{+}$ $\dot{t}+\dot{+}+\dot{i} i \dot{i} \dot{i}+\dot{+}+\dot{+}+\dot{+}+\dot{+}+\dot{+} i \dot{i}$

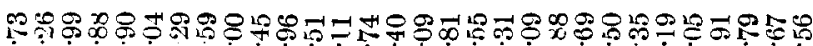
它

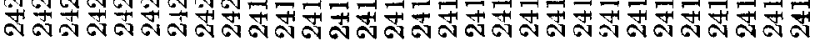

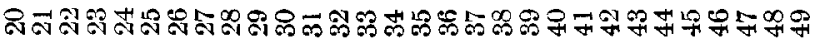

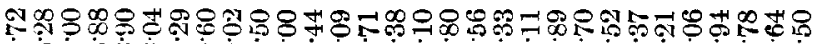
L

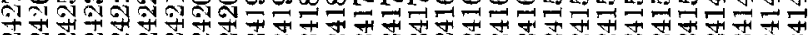

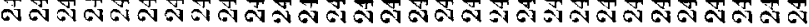


Other formulæ which have been employed (besides that of Kayser and Runge, which is not sufficient) are the Ritz form

$$
\text { O.F. }=\text { C.F. }-\frac{109675}{\left(m+\mu+\frac{c}{m^{2}}\right)^{2}},
$$

and that of Lohuizen

$$
\mathrm{O} . \mathrm{F} .=\mathrm{C} . \mathrm{F} .-\frac{109675}{\left(m+\mu+\frac{e}{\mathrm{O} . \mathrm{F} .}\right)^{2}} .
$$

A comparison of the results given by these different formulæ is calculated to afford useful guidance in the examination of less extended series.

The case of Sodium has been eximined at length by Birge *, who gives wave-lengths on the Fabry and Perot scale reduced to vacuum, and employs the Ritz formula with $109678 \cdot 6$ as the value of $\mathrm{N}$ instead of 109675 .

In the table on pp. 776-7 I give the wave-lengths calculated from the formula

$$
\text { O.F }=41448 \cdot 67-\frac{109675}{\left(m+\cdot 147408-\frac{.031328}{m-1}\right)^{2}}
$$

for the less refrangible component, and

$$
\text { O.F. }=41448 \cdot 67-\frac{109675}{\left(m+\cdot 148204-\frac{\cdot 031380}{m-1}\right)^{2}}
$$

for the more refrangible component of the pairs of lines.

In Potassium the formulæ

$$
\begin{aligned}
& \text { O.F. }=35005 \cdot 56-\frac{109675}{\left(m+\cdot 293076-\frac{.061356}{m-1}\right)^{2}}, \\
& \text { O.F. }=35005 \cdot 56-\frac{109675}{\left(m+\cdot 296228-\frac{061628}{m-1}\right)^{2}}
\end{aligned}
$$

give the following values:-

* Astrophys. Journ. xxxii. p. 112 (1910). 
in the Spectra of the Alkali Metals.

The Principal Series in Potassium.

\begin{tabular}{|c|c|c|c|c|c|c|c|c|c|}
\hline \multicolumn{5}{|c|}{ Observed. } & \multirow[b]{2}{*}{$m$} & \multirow[t]{2}{*}{$\begin{array}{l}\text { Calcu- } \\
\text { lated. }\end{array}$} & \multicolumn{3}{|c|}{ Observed_Calculated } \\
\hline \multirow{27}{*}{$\begin{array}{l}\begin{array}{l}\text { Ramage. } \\
\text { (Flame.) }\end{array} \\
\left\{\begin{array}{l}7697 \\
7664\end{array}\right. \\
\left\{\begin{array}{l}4047 \cdot 39 \\
4044 \cdot 33\end{array}\right. \\
\left\{\begin{array}{l}3447 \cdot 56 \\
3446 \cdot 55\end{array}\right. \\
\left\{\begin{array}{l}3217 \\
3217 \cdot 36\end{array}\right.\end{array}$} & \multicolumn{2}{|c|}{ Exner \& Haschek. } & Schillinger. & $\begin{array}{c}\text { Kayser \& } \\
\text { Runge. } \\
\text { Arc. }\end{array}$ & & & \multirow{2}{*}{$\begin{array}{l}+\cdot 4 \\
-\cdot 25\end{array}$} & Birge. & \multirow{7}{*}{$\begin{array}{c}\text { Hicks. } \\
\\
-4 \\
-4 \cdot 6 \\
0 \\
0 \\
0 \\
0 \\
0 \\
+.02\end{array}$} \\
\hline & & \multirow{6}{*}{$\begin{array}{l}\left\{\begin{array}{l}4047 \cdot 30 \\
4044 \cdot 30\end{array}\right. \\
3447 \cdot 6 \\
3446 \cdot 60 \\
3217 \cdot 3\end{array}$} & $\left\{\begin{array}{l}7699 \cdot 41 \\
7665 \cdot 56\end{array}\right.$ & $\left\{\begin{array}{l}7969 \cdot 3 \\
7665 \cdot 6\end{array}\right.$ & 2 & $\{7699 \cdot 10$ & & 0 & \\
\hline & $\int 4047 \cdot 42$ & & $4047 \cdot 35$ & $4047 \cdot 36$ & \multirow{2}{*}{3} & 4047.51 & -.11 & $+\cdot 01$ & \\
\hline & $\{4044 \cdot 36$ & & $\left\{\begin{array}{l}4044 \cdot 31\end{array}\right.$ & $\left\{4044.29^{\top}\right\}$ & & $4044 \cdot 13$ & $+\cdot 19$ & & \\
\hline & $\{3447 \cdot 54$ & & 3447.52 & $\{3447 \cdot 49$ & \multirow{2}{*}{4} & $\{3447 \cdot 59$ & $+\cdot 07$ & +04 & \\
\hline & i 3446.51 & & $\{3446.53$ & $\{344649$ & & |3446.56 & -02 & 1 & \\
\hline & $3217 \cdot 75$ & & $3217 \cdot 54$ & $\left\{\begin{array}{l}3217 \cdot 76 \\
3217 \cdot 27\end{array}\right.$ & 5 & $\left\{\begin{array}{l}3217 \cdot 83 \\
3217 \cdot 36\end{array}\right.$ & $\mid \begin{array}{l}-.07 \\
-.09\end{array}$ & -02 & \\
\hline & Eder \& & & & & & & & & \\
\hline & $\begin{array}{c}\text { Valenta. } \\
3102 \cdot 3\end{array}$ & & $3103 \cdot 05$ & $\left\{\begin{array}{l}3102 \cdot 37 \\
3102 \cdot 15\end{array}\right.$ & 6 & $\left\{\begin{array}{l}3102 \cdot 27 \\
3102 \cdot 00\end{array}\right.$ & $\begin{array}{l}+10 \\
+\cdot 15\end{array}$ & +.08 & $\begin{array}{l}+\cdot 21 \\
+\cdot 18\end{array}$ \\
\hline & & & & $3034 \cdot 94$ & 7 & $\left\{\begin{array}{l}3035.09 \\
3035.00\end{array}\right.$ & $-\cdot 10$ & $-\cdot 26$ & 0 \\
\hline & $2992 \cdot 3$ & $2992 \cdot 4$ & $2992 \cdot 47$ & $2992 \cdot 33$ & 8 & 299243 & $+\cdot 08$ & $-\cdot 19$ & $+\cdot 01$ \\
\hline & & & & $\begin{array}{l}2903.36 \\
29428\end{array}$ & $\begin{array}{r}9 \\
10\end{array}$ & $\begin{array}{l}2963.53 \\
2942.99\end{array}$ & $\begin{array}{l}-16 \\
-\cdot 19\end{array}$ & $\begin{array}{l}-.25 \\
-.27\end{array}$ & $\begin{array}{l}-.06 \\
-.09\end{array}$ \\
\hline & & & & Bevan. & & & & & \\
\hline & & & & $2928 \cdot 0$ & 11 & $2927 \cdot 86$ & $+\cdot 14$ & +.07 & \\
\hline & & & & $2916^{\circ} 6$ & 12 & $2916 \cdot 38$ & +22 & $+\cdot 16$ & \\
\hline & & & & $2907 \cdot 6$ & 13 & $2907 \cdot 45$ & $+\cdot 15$ & $+\cdot 09$ & \\
\hline & & & & $2900 \cdot 4$ & 14 & 290038 & +.02 & -.02 & \\
\hline & & & & 2889.7 & 16 & $\begin{array}{l}20940 \\
2890 \cdot 00\end{array}$ & -30 & $\mid$\begin{tabular}{|l}
-10 \\
-32
\end{tabular} & \\
\hline & & & & $2885 \cdot 9$ & 17 & $2886 \cdot 12$ & $-\cdot 22$ & -25 & \\
\hline & & & & $2882 \cdot 9$ & 18 & $2882 \cdot 87$ & +03 & & \\
\hline & & & & & & $2880 \cdot 12$ & $+\cdot 18$ & $+\cdot 15$ & \\
\hline & & & & 28779 & 20 & $2877 \cdot 77$ & +13 & +.09 & \\
\hline & & & & & 10 & 287575 & $\begin{array}{r}+.05 \\
\end{array}$ & +01 & \\
\hline & & & & $2872 \cdot 5$ & 22 & $\begin{array}{l}281399 \\
287246\end{array}$ & $\begin{array}{l}+.11 \\
+.04\end{array}$ & +0 & \\
\hline & & & & $2871 \cdot 1$ & 24 & $2871 \cdot 12$ & -.02 & -.04 & \\
\hline & & & & 28700 & 25 & 2869.93 & $+\cdot 07$ & $+\cdot 05$ & \\
\hline & & & & & & & & & \\
\hline
\end{tabular}

* $\left\{\begin{array}{l}7699 \cdot 32 \\ 7665 \cdot 29\end{array}\right.$ Hermann. $\quad\left\{\begin{array}{l}7699 \cdot 08 \\ 7664 \cdot 91\end{array}\right.$ Saunders. $\quad\left\{\begin{array}{l}7699 \cdot 41 \\ 7665 \cdot 39\end{array}\right.$ Eder \& Valenta. $\left\{\begin{array}{l}7701 \cdot 92 \\ 7768 \cdot 54\end{array}\right.$ Lehmann. $\left\{\begin{array}{l}4047 \cdot 571 \\ 4044.599\end{array}\right.$ Jewell. $\quad\left\{\begin{array}{l}4047 \cdot 4 \\ 4044 \cdot 3\end{array}\right.$ Eder \& Valenta.

Birge has convergence-frequency $35005 \cdot 29$, and Hicks $35006 \cdot 21$.

For Rubidium, the formulæ

$$
\begin{aligned}
& \mathrm{O} . \mathrm{F} .=33688 \cdot 20-\frac{109675}{\left(m+\cdot 352806-\frac{\cdot 073542}{m-1}\right)^{2}}, \\
& \mathrm{O} . \mathrm{F} .=33688 \cdot 20-\frac{109675}{\left(m+\cdot 365934-\frac{073868}{m-1}\right)^{2}}
\end{aligned}
$$


780 Dr. Marshall Watts on the Principal Series give the following results :-

The Principal Series in Rubidium.

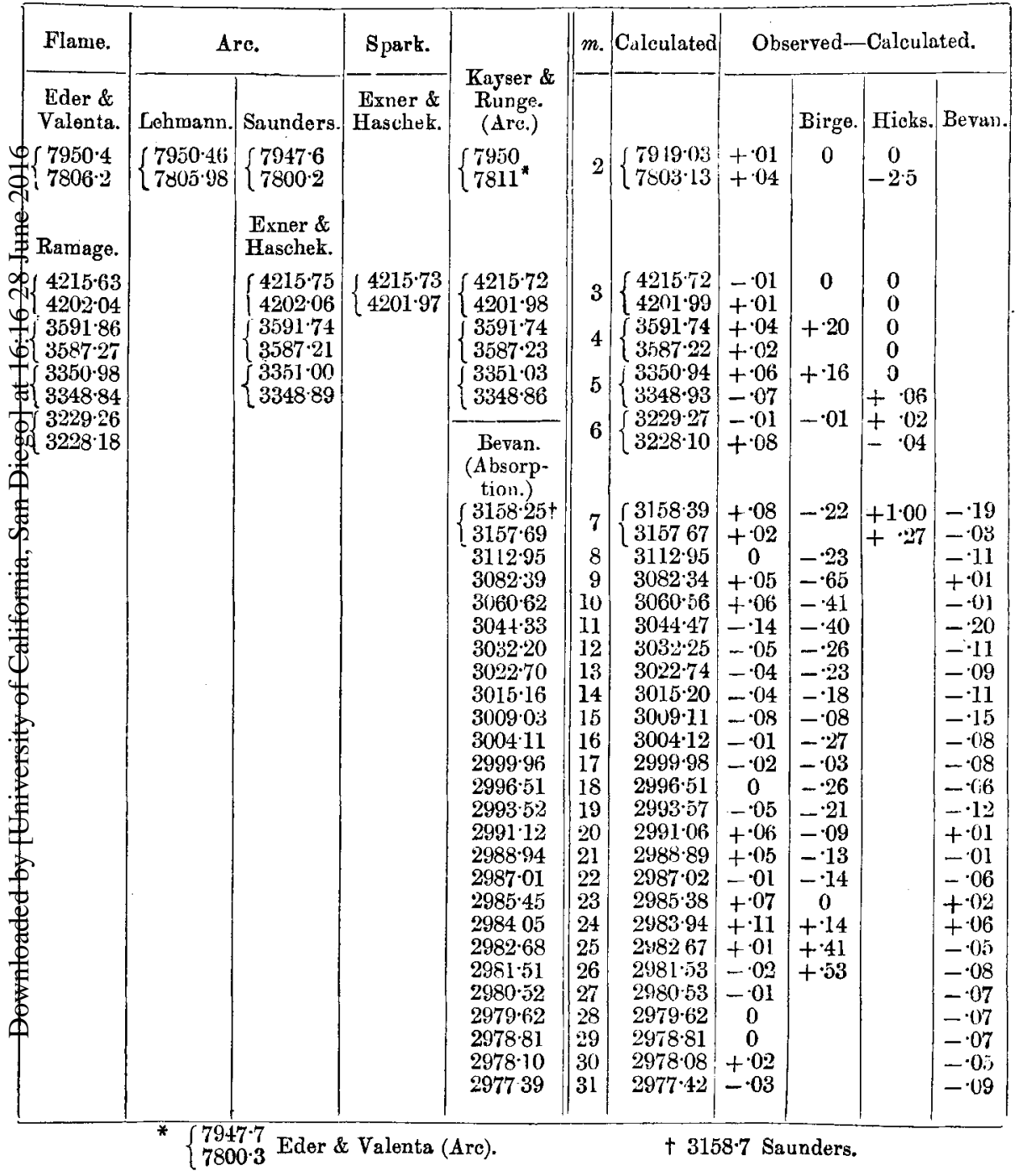

Birge has the convergence-frequency $33687 \cdot 82$, Hicks $33687 \cdot 50$, and Bevan 33687.5.

For Cæsium the formulæ

$$
\text { O.F. }=31404 \cdot 31-\frac{109675}{\left(m+418202-\frac{\cdot 090052}{m-1}\right)^{2}},
$$


in the Spectra of the Alkali Metals.

give the following results:

$$
\text { O.F. }=31404 \cdot 31-\frac{109675}{\left(m+\cdot 449969-\frac{\cdot 089326}{m-1}\right)^{2}}
$$

The Principal Series in Cæsium.

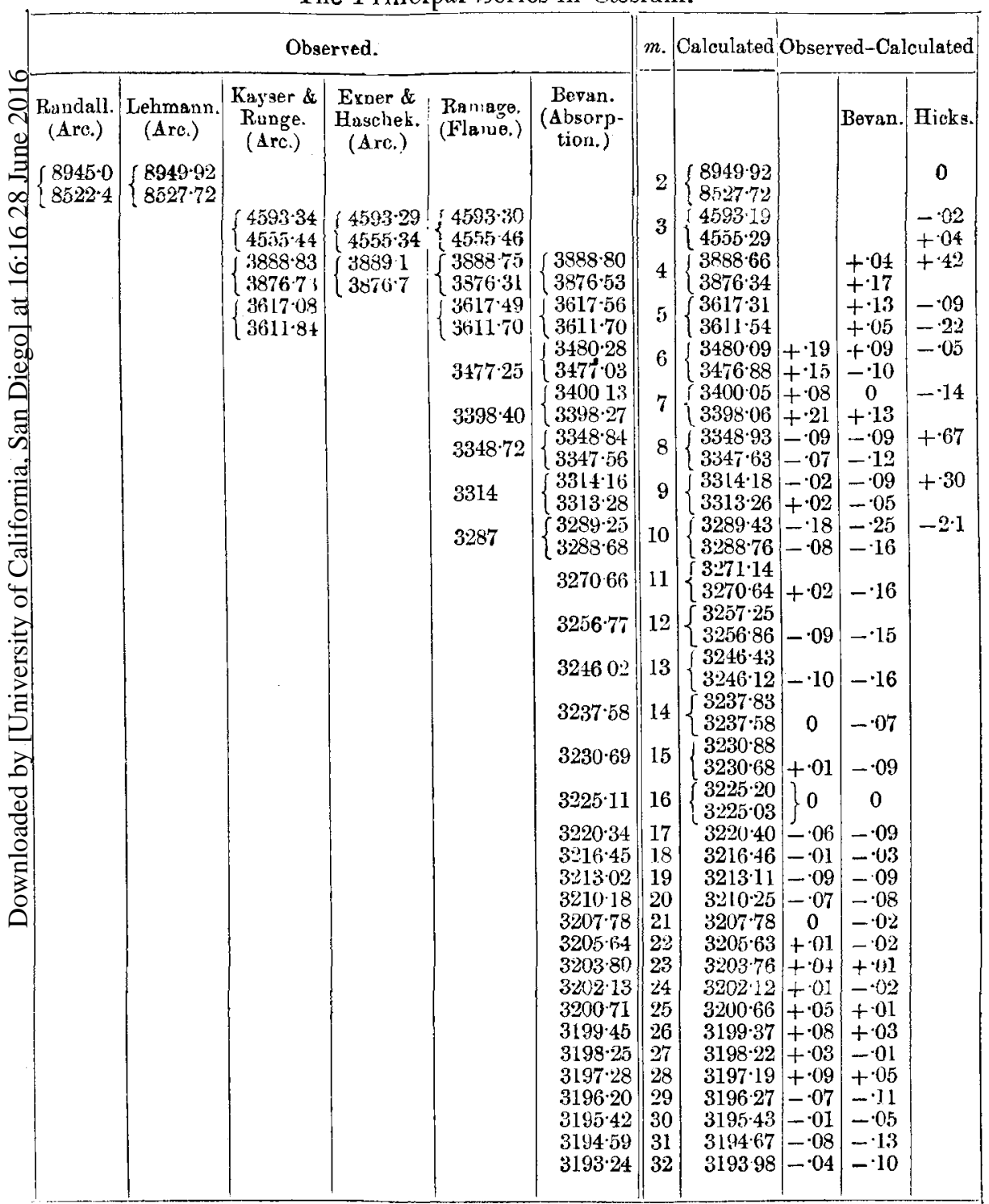


If we take the mean observed value of the first line $6708 \cdot 12$, which corresponds to the oscillation-frequency 14903.26 in vacuo, and, applying the Rydberg-Schuster rule, add $28579 \cdot 71$, Hicks's mean ralue for the convercencefrequency of the subordinate series, we obtain 43482.97 for the convergence-frequency of the principal series.

\section{IXXXII. Tonization by Positive Rays. By Norman Campbel.}

1. TTHE chief facts concerning the ionization of gases by electrons seem to be now thoroughly established, but comparatively little is known concerning ionization by the impact of atoms except when the atoms are those constituting $\alpha$-rays. The first direct attack on this problem is described in the recent papers of $v$. Bahr and Franck $\dagger$ and of Pawlow $f$, who come to the surprising conclusion that the positively charged particles from hot platinum and hot phosphates can ionize gases when their energy is less than that required by electrons. This result is of the greatest importance for theories of the structure of the atom, for it would seem to indicate that the "ionization potential" for electrons has not the fundamental significance which has often been attributed to it ; it appears that further experiments, especially on the variation of the ionizing power of positive particles with their speed, energy or charge, are desirable.

It is not easy to conduct such quantitative experiments on a gas, into which rays of such low speed as are here considered have practically no power of penetration. Bat recent work has tended to show $\S$ that the liberation of electrons, which takes place when ionizing rays of any kind fall on a metal surface, varies with the properties of those rays in precisely the same manner as the ionization which the rays cause in a gas. Indeed it is highly probable that, when the surface of the metal bas been recently polished, the electrons are actually liberated from a layer of gas on the surface of the metal. Experiments on such metal surfaces are free from many of the difficulties which attend experiments on ionization in a gas which has any appreciable volume.

* Communicated by the Author.

† E. v. Bahr and J. Franck, Deutsch. Phys. Gesell. Verh. xvi. 1. p. 57 (1914).

I W. Pawlow, Roy. Soc. Proc. A. vol, xe. p. 898 (1914).

5 See, e.g., N. Campbell, Phil. Mag. June 1913, p. 803, and March 1915, p. 369. 